\title{
Erratum to: Engineering Interactive Systems
}

Jan Gulliksen ${ }^{1}$, Morton Borup Harning ${ }^{2}$, Philippe Palanque ${ }^{3}$, Gerrit C. van der Veer ${ }^{4}$, and Janet Wesson ${ }^{5}$

1 Uppsala University, Uppsala, Sweden jan.gulliksen@it.uu.se

2 Priway ApS, Lyngby, Denmark harning@se-hci.org

3 Institute of Research in Informatics of Toulouse (IRIT),

University Paul Sabatier, Toulouse, France

palanque@irit.fr

4 School of Computer Science, Open Universiteit Nederland, Heerlen, The Netherlands

Gerrit.vanderVeer@ou.nl

5 Nelson Mandela Metropolitan University, Port Elizabeth, South Africa

janet.wesson@nmmu.ac.za

\section{Erratum to:}

J. Gulliksen et al. (Eds.)

Engineering Interactive Systems

DOI: $10.1007 / 978-3-540-92698-6$

The book was inadvertently published with an incorrect name of the copyright holder. The name of the copyright holder for this book is: (c) Springer-Verlag Berlin Heidelberg. The book has been updated with the changes.

The updated original online version for this book can be found at DOI: $10.1007 / 978-3-540-92698-6$

J. Gulliksen et al. (Eds.): EIS 2007, LNCS, p. E1, 2008.

(C) Springer-Verlag Berlin Heidelberg 2017 